\title{
Comparative mapping of the 22q11.2 deletion region and the potential of simple model organisms
}

\author{
Alina Guna ${ }^{1}$, Nancy J. Butcher ${ }^{1,2}$ and Anne S. Bassett ${ }^{1,2,3,4,5^{*}}$
}

\begin{abstract}
Background: 22q11.2 deletion syndrome (22q11.2DS) is the most common micro-deletion syndrome. The associated 22q11.2 deletion conveys the strongest known molecular risk for schizophrenia. Neurodevelopmental phenotypes, including intellectual disability, are also prominent though variable in severity. Other developmental features include congenital cardiac and craniofacial anomalies. Whereas existing mouse models have been helpful in determining the role of some genes overlapped by the hemizygous 22q11.2 deletion in phenotypic expression, much remains unknown. Simple model organisms remain largely unexploited in exploring these genotype-phenotype relationships.

Methods: We first developed a comprehensive map of the human 22q11.2 deletion region, delineating gene content, and brain expression. To identify putative orthologs, standard methods were used to interrogate the proteomes of the zebrafish (D. rerio), fruit fly (D. melanogaster), and worm (C. elegans), in addition to the mouse. Spatial locations of conserved homologues were mapped to examine syntenic relationships. We systematically cataloged available knockout and knockdown models of all conserved genes across these organisms, including a comprehensive review of associated phenotypes.
\end{abstract}

Results: There are 90 genes overlapped by the typical $2.5 \mathrm{Mb}$ deletion 22q11.2 region. Of the 46 protein-coding genes, 41 (89.1\%) have documented expression in the human brain. Identified homologues in the zebrafish $(n=37,80.4 \%)$ were comparable to those in the mouse $(n=40,86.9 \%)$ and included some conserved gene cluster structures. There were 22 (47.8\%) putative homologues in the fruit fly and 17 (37.0\%) in the worm involving multiple chromosomes. Individual gene knockdown mutants were available for the simple model organisms, but not for mouse. Although phenotypic data were relatively limited for knockout and knockdown models of the 17 genes conserved across all species, there was some evidence for roles in neurodevelopmental phenotypes, including four of the six mitochondrial genes in the 22q11.2 deletion region.

Conclusions: Simple model organisms represent a powerful but underutilized means of investigating the molecular mechanisms underlying the elevated risk for neurodevelopmental disorders in 22q11.2DS. This comparative multi-species study provides novel resources and support for the potential utility of non-mouse models in expression studies and high-throughput drug screening. The approach has implications for other recurrent copy number variations associated with neurodevelopmental phenotypes.

Keywords: DiGeorge syndrome, Velocardiofacial syndrome, Animal models, Homology, Homolog, DGCR8, PRODH, SLC25A1, TBX1

\footnotetext{
* Correspondence: anne.bassett@utoronto.ca

${ }^{1}$ Clinical Genetics Research Program and Campbell Family Mental Health Research Institute, Centre for Addiction and Mental Health, Toronto, ON, Canada

${ }^{2}$ Institute of Medical Science, University of Toronto, Toronto, ON, Canada Full list of author information is available at the end of the article
}

\section{Biomed Central}

(c) 2015 Guna et al. This is an Open Access article distributed under the terms of the Creative Commons Attribution License (http://creativecommons.org/licenses/by/4.0), which permits unrestricted use, distribution, and reproduction in any medium, provided the original work is properly credited. The Creative Commons Public Domain Dedication waiver (http:// creativecommons.org/publicdomain/zero/1.0/) applies to the data made available in this article, unless otherwise stated. 


\section{Background}

22q11.2 deletion syndrome (22q11.2DS, MIM \#188400/ \#192430) is the most common micro-deletion syndrome in humans with an estimated prevalence of at least 1 in 4000 live births $[1,2]$. Formerly known as velocardiofacial or DiGeorge syndrome, this multi-system condition is associated with a broad range of developmental features including congenital cardiac and palatal anomalies, intellectual disabilities, hypoparathyroidism, and subtle facial dysmorphism [2-4]. Developmental delay and later onset disorders affecting the nervous system are particularly common [5]. These include attention deficit hyperactivity disorder [6, 7], anxiety disorders $[8,9]$, autism $[10,11]$, epilepsy, schizophrenia $[2,12]$, and early-onset Parkinson's disease $[13,14]$. The phenotypic manifestations of the syndrome are thought to be related at least in part to reduced gene dosage in the $22 \mathrm{q} 11.2$ deletion region that in turn interferes with normal protein functioning [15].

The typical associated $\sim 2.5 \mathrm{Mb} 22 \mathrm{q} 11.2$ deletion is present in $>85 \%$ of individuals with 22q11.2DS $[16,17]$, while a smaller proximal nested $\sim 1.5 \mathrm{Mb}$ deletion occurs in $\sim 10 \%$ of cases $[18,19]$. The associated $22 q 11.2$ deletions are mediated by segmental duplications, or low-copy repeats (LCRs) that confer susceptibility of the region to copy number variation through non-allelic homologous recombination $[20,21]$. The penetrance and variable expressivity of major associated phenotypes appear to be largely independent of deletion size [22, 23]. The few mRNA sequencing and protein expression studies of individuals with 22q11.2DS published to date [24-33] illustrate the complexity of linking specific genes to the phenotypes associated with this disorder. Much remains to be known about the individual and collective roles of 22q11.2 deletion region genes in modulating associated phenotypes. Model animals will undoubtedly play an essential role in this discovery process.

Mouse models have already been proven useful for characterizing the molecular function of 22q11.2 genes and establishing a link between certain genes and 22q11.2DS associated phenotypes [34]. The syntenic region on mouse chromosome 16 has a high degree of gene conservation to the human 22q11.2 region. Current engineered mouse models include deletions of large portions of the syntenic region and mutations of individual genes [34, 35]. However, simple model organisms could also prove to be powerful tools for investigating genomic disorders such as 22q11.2DS. Their ease of genetic manipulation, amenability to high-throughput behavioural screening, and short generation times make simple organisms attractive potential resources. The potential for simple model organisms to reveal the genetic mechanisms underlying 22q11.2DS phenotypes remains essentially unexamined however.

As an initial step in determining the utility of simple model organisms in the study of 22q11.2DS, we generated an updated, comprehensive 22q11.2DS human gene map and investigated the evolutionary conservation status of genes within the 22q11.2 region in three common model organisms: the zebrafish, Danio rerio (D. rerio), the fruit fly, Drosophila melanogaster (D. melanogaster), and the worm, Caenorhabditis elegans (C. elegans). We included the otherwise well-reviewed mouse models [34, 35] for comparison. We then conducted a comprehensive review of gene function and phenotypic alterations related to 22q11.2 gene homologue disruptions and developed a novel comprehensive resource of available knockout and knockdown models. The results may help to accelerate the identification of novel genotype-phenotype correlations in 22q11.2DS and inform pathogenesis of, and drug development for this disorder and its commonly associated features.

\section{Methods}

\section{Human 22q11.2 region characterization}

The human 22q11.2DS deletion region, genetic content, and order were mapped from NCBI Gene Homo sapiens Annotation Release 105 using Affymetrix CytoScan HD (Santa Clara, CA, USA) array mean breakpoints (chr22:18,820, 303-21, 489,474) ascertained from 16 patients with confirmed 22q11.2 deletions (Fig. 1). Fourteen of the 16 patients had deletions covering most of the 22q11.2 region $(\sim 2.5 \mathrm{Mb})$ while two had smaller, nested proximal deletions. The same region was obtained with a larger, previously described patient population $(n=99)$ using Affymetrix $\mathrm{Hu}-$ man SNP 6.0 breakpoints [3, 36]. All patients provided consent and the study was approved by local research ethics boards [3]. We accessed the Database of Genomic Variants to establish the corresponding locations of major UCSC segmental duplications across the deletion region (http:// dgv.tcag.ca/dgv/app/home; accessed 1 December 2014). Build GRCh37 gene coordinates were used to ensure congruency across all databases used in this study. We omitted the few genes that move outside the 22q11.2 deletion region in build GRCh38 (i.e., the segment flanked by proteincoding genes TMEM191B...RIMBP3).

To identify changes in gene expression conferred by 22q11.2 hemizygosity, a systematic literature review (current to 1 December 2014) was conducted using PubMed to identify experimentally validated changes in 22q11.2 region gene expression (mRNA) in patients with 22q11.2DS. The following search terms were used: "22q11.2 deletion syndrome", "22q11.2DS", "DiGeorge syndrome", "velo-cardio-facial syndrome", "velocardiofacial syndrome", "VCFS", "CATCH22", and "Shprintzen syndrome", in conjunction with the name of each gene (and all associated gene aliases from GenBank). The Human Brain Transcriptome (http://hbatla s.org/) was used to identify genes expressed in the brain (mRNA signal $\geq 6$ ) across the lifespan in any brain region [37]. For genes $(n=10)$ not found in the Human Brain 
RefSeq Genes chr22: 18,630,000 - 21,810,000 (GRCh37/hg19)

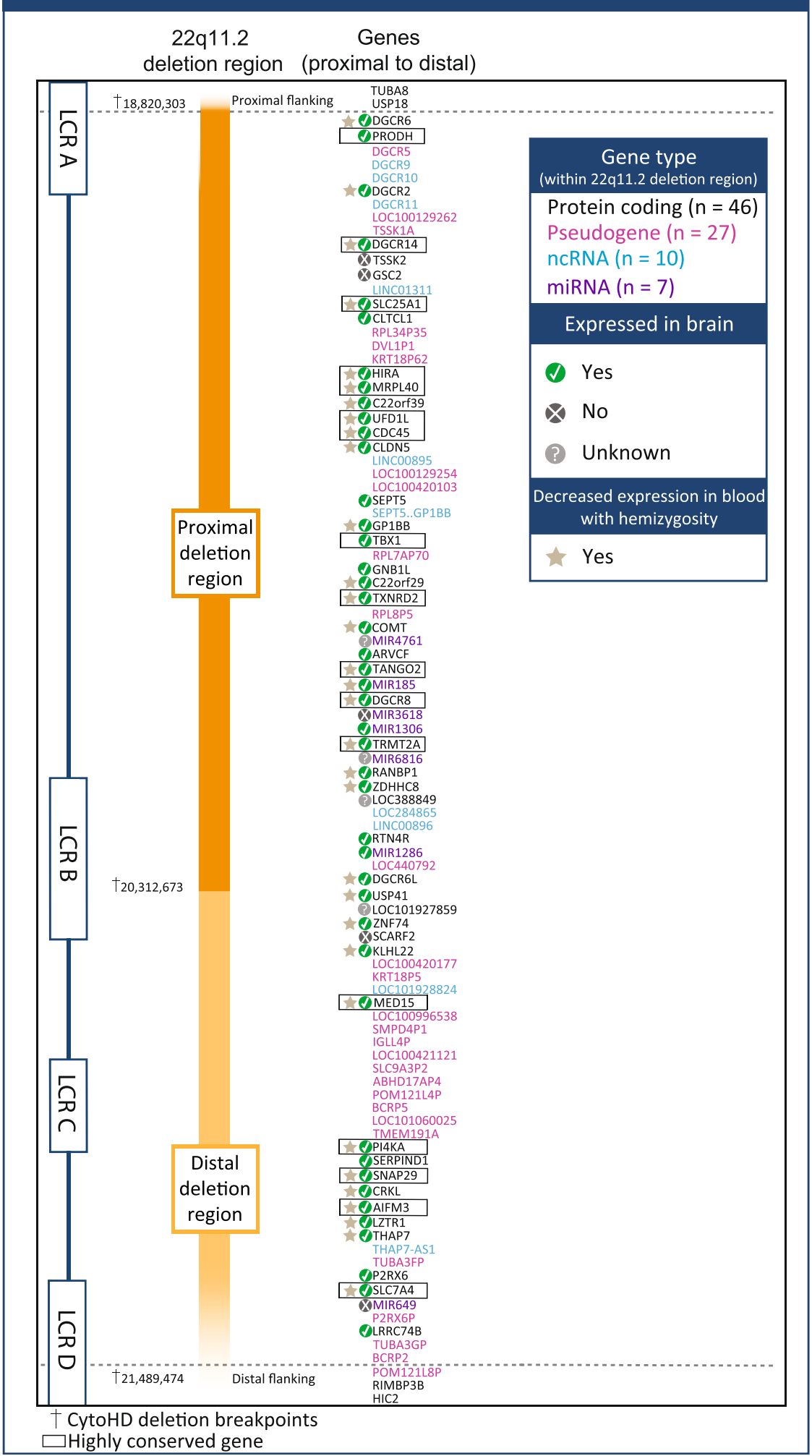

Fig. 1 (See legend on next page.) 
(See figure on previous page.)

Fig. 1 Genetic landscape of the human 22q11.2 region. The typical 2.5-Mb 22q11.2DS deletion spans 90 RefSeq genes (see text for details). Region breakpoints are mediated by four chromosome specific low-copy repeats (LCRA-D; approximate locations shown). Gene expression, indicated by a green circled check mark, was established using The Human Brain Transcriptome. Data for decreased expression with hemizygosity were collated from experimentally demonstrated [24, 28-33] reductions in gene expression in blood cells from patients with 22q11.2DS. Gene names within a rectangle denote the 17 genes conserved across the mouse, zebrafish, fruit fly, and worm

Transcriptome, UniProtKB (http://www.uniprot.org/uniprot/) and associated gene expression databases (ArrayExpress, Bgee and CleanEx) were consulted.

\section{Gene conservation and function in model species}

To identify putative orthologs of human 22q11.2 region protein-coding genes in the zebrafish $(D$. rerio), fruit fly (D. melanogaster), worm (C. elegans), and mouse (M. musculus), we employed the reciprocal best hits method, i.e., the protein products of genes in two different genomes represent the best hit in the opposite genome, using protein Basic Local Alignment Search Tool (blastp) analysis with the UniProtKB database (http://www.uniprot.org/uni prot/) including both Swiss-Prot and TrEMBL entries (accessed 1 December 2014). We ran blastp using each of the 46 22q11.2 deletion region protein-coding genes as a query against all proteins annotated in each genome of interest, using default settings and a maximum $E$-value threshold of $1 \times 10^{-6}[38,39]$. We also required coverage of at least $50 \%$ of any of the protein sequences in the alignments. In instances of multiple protein isoforms due to alternative splicing, the "canonical" sequence, as identified by UniProtKB, was selected for blastp analysis. To find orthologs as reciprocal best hits, we sorted blastp hits from the highest to the lowest bit score. Using this sorting method, the first hit was therefore the best hit. If the next hit had the very same score, there would be more than one hit (the method can therefore produce multiple orthologs). The same procedure was performed in the opposite direction. In the zebrafish, an organism that has undergone genomewide duplication, we included multiple hits if the scores of putative homologues were very similar, and both hits were consistently identified across multiple databases (e.g., RefSeq). NCBI Entrez Gene was then used to individually search all putative orthologs to establish organism-specific gene location (Additional file 1). The conservation status of the seven 22q11.2 region miRNAs identified was examined using miRBase21 (accessed in December 2014) [40]. Human non-coding genes $(n=10)$ including one readthrough transcript, and pseudogenes $(n=27)$ in the 22q11.2 deletion region were not investigated further.

To identify available knockout and knockdown models of the identified 22q11.2 region homologues and collate their phenotypic manifestations, we conducted a systematic search (accessed 1 December 2014) of species-specific databases including: WormBase (http://www.wormbase.org/), FlyBase (http://flybase.org/), ZFin (http://zfin.org/), and
MGI (http://www.informatics.jax.org/) databases for C. elegans, D. melanogaster, D. rerio, and M. musculus, respectively. A secondary PubMed literature review confirmed that all studies examining orthologs in our model organisms of interest were included. Knockouts (homozygote) were defined as mutant models that did not produce a functional protein product due to a premature stop codon, a disruptive insertion, or full excision of a gene. For all model organisms discussed, we note only the availability of homozygous knockouts; these are more difficult to generate and are required for heterozygous knockout animals (the result of a cross of a homozygous knockout with a wild-type strain). We have however provided the known phenotypes of heterozygous knockout models for genes conserved across all examined organisms. Knockdown models were defined as those with reduced gene expression induced by any technology that interfered with the translation of a gene after it had been transcribed. The 17 genes conserved across model organisms were examined to document the availability of phenotypic information of mutant models. Single gene mutations have been reported in humans for 22q11.2DS genes, however these were outside the scope of this study.

\section{Results}

Characterization of the human 22q11.2 deletion region

The typical human 22q11.2 deletion overlapped 90 genes, and the smaller proximal $\sim 1.5 \mathrm{Mb}$ deletion encompassed 55 of these genes (Fig. 1). Just over half ( $n=46,51.1 \%)$ of these 90 genes are protein-coding and of these, most $(n=41,89.1 \%)$ are expressed in the human brain. For the proximal nested deletion, there were 30 protein-coding genes, 27 (90.0\%) of which are expressed in the brain. We identified seven studies documenting gene expression in 22q11.2DS patients. These collectively demonstrated decreased expression of 32 (69.6 \%) 22q11.2 region proteincoding genes [24, 28-33] in blood cells from patients with 22q11.2DS relative to non-deleted controls (Fig. 1). Three genes (TBX1, RTN4R, and P2RX6P) are not expressed in blood, [24] and the remaining 11 (23.9\%) remain to be studied in this context.

In the typical 22q11.2 region, there were also 27 pseudogenes, one read-through transcript (classified as a noncoding RNA) (SEPT5...GP1BB), nine non-coding RNA genes, and seven microRNAs (miRNAs; Fig. 1). Recent studies propose that the miRNA processing protein Pasha, encoded by $D G C R 8$, which lies within the 22q11.2 deletion 
region, may play a role in modifying genome-wide expression of target genes that contribute to the neuropsychiatric phenotypes associated with 22q11.2DS, together with the region's high density of miRNAs [36, 41-43]. Three of the seven miRNAs (MIR185, MIR1306, MIR1286) have been found to be expressed in the brain, while two were not (MIR3618, MIR649), [44] and the other two (MIR4761, MIR6816) have yet to be investigated.

\section{2q11.2 region gene conservation in model organisms}

The well-studied mouse syntenic region of the human proximal $(1.5 \mathrm{Mb})$ deletion located on chromosome 16 (MMU 16qA13; Fig. 2) contained 27 of the 30 human protein-coding genes localized to the human proximal deletion region (Fig. 1), the exceptions being clathrin, heavy chain-like 1 (CLTCL1), chromosome 22 open reading frame 29 (C22orf29), and DiGeorge syndrome critical region-6like (DGCR6L). With respect to the typical $2.5 \mathrm{Mb}$ deletion,
40 of the 46 protein-coding genes are conserved in the mouse (Fig. 2).

The zebrafish also exhibited a high degree of gene conservation to the human 22q11.2DS region. In total, 37 (80.4 \%) of the 46 protein-coding human homologues had putative homologues in the zebrafish (Table 1 , Fig. 2). Compared to the genes contained in the human 22q11.2 region, the fruit fly had available homologues for $22(47.8 \%)$ protein-coding genes, and the worm had 17 (37.0 \%) available homologues.

Seventeen genes were conserved across all three of the simple model species (Table 1) and in mice. By human position, these are as follows: PRODH, DGCR14, SLC25A1, HIRA, MRPL40, UFD1L, CDC45, TBX1, TXNRD2, TANGO2, DGCR8, TRMT2A, MED15, PI4KA, SNAP29, AIFM3, SLC7A4 (Fig. 2). Notably, 16 (94.1\%) of these are expressed in the human brain (Fig. 1), five of which encode mitochondrial proteins (PRODH, SLC25A1, MRPL40, TXNRD2, TANGO2). In the zebrafish, there were five genes (PRODH, SLC25A1,

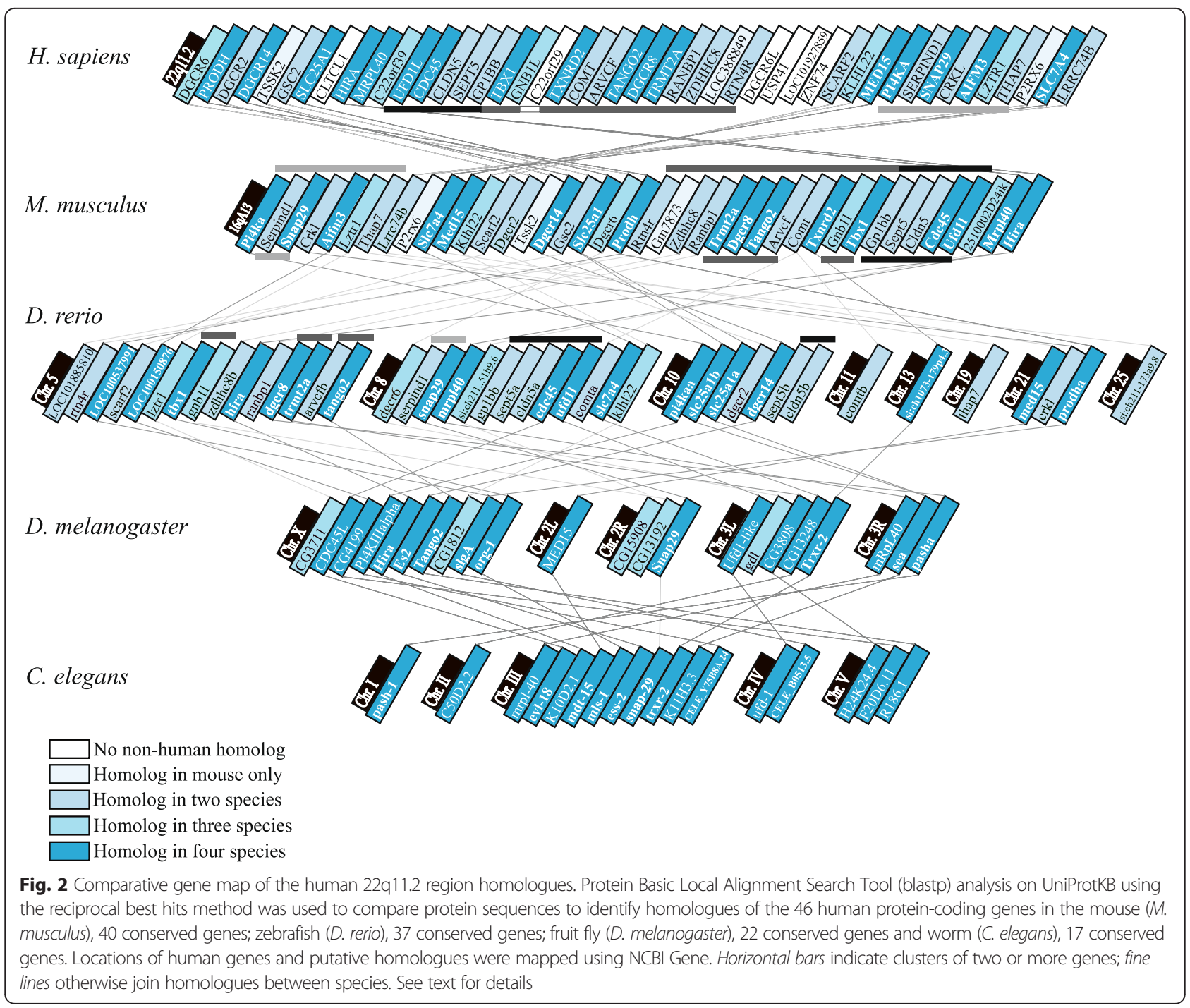


Table 1 Conservation status and available knockout (KO)/knockdown (KD) models of 22q11.2 deletion region protein-coding genes

\begin{tabular}{|c|c|c|c|c|c|c|c|c|c|c|c|c|}
\hline \multirow{2}{*}{$\begin{array}{l}\text { Human protein- } \\
\text { coding gene }^{a}\end{array}$} & \multicolumn{3}{|l|}{ C. elegans } & \multicolumn{3}{|c|}{ D. melanogaster } & \multicolumn{3}{|l|}{ D. rerio } & \multicolumn{3}{|l|}{ M. musculus } \\
\hline & $\begin{array}{l}\text { Homologue } \\
(n=17)\end{array}$ & $\%$ & Model $^{b}$ & $\begin{array}{l}\text { Homologue } \\
(n=22)\end{array}$ & $\%$ & Model $^{b}$ & $\begin{array}{l}\text { Homologue } \\
(n=37)\end{array}$ & $\%$ & Model $^{b}$ & $\begin{array}{l}\text { Homologue } \\
(n=40)\end{array}$ & $\%$ & Model $^{b}$ \\
\hline DGCR6 & & & & gdl & 37 & $\mathrm{KO}$ & dgcr6 & 65 & - & Dgcr6 & 92 & - \\
\hline \multirow[t]{2}{*}{ PRODH } & CELE_B0513.5 & 46 & KD & slgA & 46 & $\mathrm{KO}, \mathrm{KD}$ & LOC100537991 & 69 & - & Prodh & 82 & $\mathrm{KO}$ \\
\hline & & & & & & & prodha & 63 & $\mathrm{KO}$ & & & \\
\hline DGCR2 & & & & & & & dgcr2 & 64 & $\mathrm{KO}$ & Dgcr2 & 93 & $\mathrm{KO}$ \\
\hline DGCR14 & ess-2 & 30 & $\mathrm{KO}, \mathrm{KD}$ & Es2 & 35 & $\mathrm{KD}$ & dgcr14 & 67 & - & Dgcr14 & 93 & $\mathrm{KO}$ \\
\hline TSSK2 & & & & & & & & & & Tssk2 & 92 & $\mathrm{KO}$ \\
\hline GSC2 & & & & & & & LOC101885810 & 52 & - & Gsc2 & 76 & $\mathrm{KO}$ \\
\hline \multirow[t]{2}{*}{ SLC25A1 } & $\mathrm{K} 11 \mathrm{H} 3.3$ & 65 & $K D$ & sea & 67 & $\mathrm{KO}, \mathrm{KD}$ & slc25a1a & 78 & $\mathrm{KD}$ & Slc25a1 & 94 & $\mathrm{KO}$ \\
\hline & & & & & & & slc25a1b & 84 & - & & & \\
\hline HIRA & K10D2.1 & 33 & $\mathrm{KO}, \mathrm{KD}$ & Hira & 60 & $\mathrm{KO}, \mathrm{KD}$ & hira & 78 & $\mathrm{KD}$ & Hira & 96 & $\mathrm{KO}$ \\
\hline MRPL4O & mrpl-40 & 30 & KD & mRpL40 & 40 & $\mathrm{KO}, \mathrm{KD}$ & mrpl40 & 50 & - & Mrpl40 & 75 & $\mathrm{KO}$ \\
\hline C22orf39 & & & & CG15908 & 32 & $\mathrm{KO}, \mathrm{KD}$ & si:ch211..51 h9.6 & 49 & - & 2510002D24Rik & 72 & $\mathrm{KO}$ \\
\hline UFD1L & ufd-1 & 41 & KD & Ufd1-like & 56 & $\mathrm{KO}, \mathrm{KD}$ & ufd11 & 87 & $\mathrm{KO}$ & Ufd1I & 99 & $\mathrm{KO}$ \\
\hline$C D C 45$ & evl-18 & 29 & $\mathrm{KO}, \mathrm{KD}$ & CDC45L & 39 & $\mathrm{KO}, \mathrm{KD}$ & cdc45 & 74 & $\mathrm{KO}$ & Cdc45 & 92 & $\mathrm{KO}$ \\
\hline \multirow[t]{2}{*}{ CLDN5 } & & & & & & & cldn5a & 57 & $\mathrm{KO}, \mathrm{KD}$ & Cldn5 & 92 & $\mathrm{KO}$ \\
\hline & & & & & & & cldn5b & 54 & - & & & \\
\hline \multirow[t]{2}{*}{ SEPT5 } & & & & & & & sept5a & 84 & - & Sept5 & 99 & $\mathrm{KO}$ \\
\hline & & & & & & & sept $5 b$ & 85 & - & & & \\
\hline GP1BB & & & & & & & gp1bb & 46 & - & Gp1bb & 90 & $\mathrm{KO}$ \\
\hline$T B \times 1$ & mls-1 & 53 & $\mathrm{KO}, \mathrm{KD}$ & org-1 & 58 & $\mathrm{KO}, \mathrm{KD}$ & $\mathrm{tb} \times 1$ & 72 & $\mathrm{KO}, \mathrm{KD}$ & Tbx1 & 91 & $\mathrm{KO}$ \\
\hline GNB1L & & & & CG13192 & 30 & $\mathrm{KO}, \mathrm{KD}$ & gnb1l & 53 & - & Gnb1l & 82 & $\mathrm{KO}$ \\
\hline TXNRD2 & $\operatorname{trxr}-2$ & 49 & $\mathrm{KO}, \mathrm{KD}$ & Trxr-2 & 55 & $\mathrm{KD}$ & si:ch1073-179p4.3 & 71 & - & Txnrd2 & 86 & $\mathrm{KO}$ \\
\hline \multirow[t]{2}{*}{ COMT } & & & & & & & comta & 53 & - & Comt & 80 & $\mathrm{KO}$ \\
\hline & & & & & & & comtb & 54 & - & & & \\
\hline ARVCF & & & & & & & arvcfb & 64 & $\mathrm{KO}$ & Arvcf & 92 & $\mathrm{KO}$ \\
\hline TANGO2 & R186.1 & 29 & KD & Tango2 & 30 & $\mathrm{KO}, \mathrm{KD}$ & tango2 & 64 & - & Tango2 & 88 & - \\
\hline$D G C R 8$ & pash-1 & 25 & $\mathrm{KO}, \mathrm{KD}$ & pasha & 37 & $\mathrm{KO}, \mathrm{KD}$ & dgcr8 & 72 & $\mathrm{KO}$ & Dgcr8 & 95 & $\mathrm{KO}$ \\
\hline TRMT2A & $\mathrm{H} 24 \mathrm{~K} 24.4$ & 27 & KD & CG3808 & 37 & $\mathrm{KO}, \mathrm{KD}$ & trmt2a & 56 & $\mathrm{KO}$ & Trmt2a & 83 & $\mathrm{KO}$ \\
\hline RANBP1 & & & & & & & ranbp1 & 73 & $\mathrm{KO}$ & Ranbp1 & 93 & $\mathrm{KO}$ \\
\hline ZDHHC8 & & & & & & & zdhhc8b & 57 & $\mathrm{KO}$ & Zdhhc8 & 92 & $\mathrm{KO}$ \\
\hline LOC388849 & & & & & & & & & & Gm7873 & 72 & - \\
\hline RTN4R & & & & & & & $r \operatorname{tn} 4 r$ & 45 & $K D$ & Rtn4r & 89 & $\mathrm{KO}$ \\
\hline SCARF2 & & & & & & & scarf2 & 52 & - & Scarf2 & 82 & $\mathrm{KO}$ \\
\hline KLHL22 & & & & CG1812 & 30 & $\mathrm{KO}, \mathrm{KD}$ & klhl22 & 60 & - & Klhl22 & 95 & - \\
\hline MED15 & mdt- $15^{c}$ & 26 & $\mathrm{KO}, \mathrm{KD}$ & MED15 & 32 & $\mathrm{KO}, \mathrm{KD}$ & $\operatorname{med} 15^{b}$ & 60 & $\mathrm{KD}$ & Med15 & 90 & - \\
\hline PIAKA & CELE_Y75B8A.24 & 38 & $\mathrm{KO}, \mathrm{KD}$ & PI4KIIllalpha & 45 & $\mathrm{KO}, \mathrm{KD}$ & pi4kaa & 84 & $\mathrm{KD}$ & Pi4ka & 98 & $\mathrm{KO}$ \\
\hline SERPIND1 & & & & & & & serpind1 & 54 & - & Serpind1 & 82 & $\mathrm{KO}$ \\
\hline SNAP29 & snap-29 & 28 & $\mathrm{KO}, \mathrm{KD}$ & Snap29 & 32 & $\mathrm{KO}, \mathrm{KD}$ & snap29 & 51 & $\mathrm{KD}$ & Snap29 & 83 & $\mathrm{KO}$ \\
\hline CRKL & & & & & & & crkl & 82 & $K D$ & Crkl & 97 & $\mathrm{KO}$ \\
\hline AIFM3 & F20D6.11 & 34 & KD & CG4199 & 38 & $\mathrm{KO}, \mathrm{KD}$ & LOC100150876 & 66 & - & Aifm3 & 96 & - \\
\hline LZTR1 & & & & CG3711 & 51 & $\mathrm{KO}, \mathrm{KD}$ & Iztr1 & 81 & - & Lztr1 & 95 & $\mathrm{KO}$ \\
\hline THAP7 & & & & & & & thap7 & 42 & $\mathrm{KO}$ & Thap7 & 93 & - \\
\hline
\end{tabular}


Table 1 Conservation status and available knockout (KO)/knockdown (KD) models of 22q11.2 deletion region protein-coding genes (Continued)

\begin{tabular}{llllllllllllllll}
\hline P2RX6 & & & & & & P2rx6 & & 86 & KO \\
SLC7A4 & C50D2.2 & 43 & KD & CG13248 & 43 & KO, KD & slc7a4 & 64 & KO & Slc7a4 & 84 & - \\
LRRC74B & & & & & & & si:ch211-173a9.8 & 41 & - & LrrC74b & 68 & - \\
\hline
\end{tabular}

${ }^{a}$ Genes ordered by proximal to distal 22q11.2 locus position. Genes CLTCL1, C22orf29, DGCR6L, USP41, LOC101927859, and ZNF74 have no putative homologues, and are therefore not shown

${ }^{\mathrm{b}}$ Knockout indicates a homozygous knockout model (heterozygous knockout models can be generated by crossing a homozygous knockout with a wild-type strain) ' Included due to confirmed functional homology [98], although did not meet minimal protein sequence coverage requirement at $50 \%$ Italicized genes have putative homologues across all four model organisms $(n=17)$. Blank cells indicate no identified homologue; - indicates no knockout (KO) or knockdown (KD) model available. Percent (\%) indicates sequence similarity to human protein. Homologues were identified using blastp using the UniProtKB database. KO and KD models were identified from WormBase (http://www.wormbase.org/), FlyBase (http://flybase.org/), ZFin (http://zfin.org/), and MGI (http://www.informatics.jax.org/) for C. elegans, D. melanogaster, D. rerio, and M. musculus, respectively. Data are current to 2 December 2014

CLDN5, SEPT5, COMT) where multiple putative homologues were identified, likely due to gene locus duplication [45] (Table 1; Fig. 2).

Certain genes maintained positional proximity across species (Fig. 2; Additional file 1), indicating some conserved synteny [46] (e.g., with minimal shuffling of order, from human $T B X 1$ to $Z D H H C 8$, with an intact core from $H I R A$ to $G N B 1 L$, to mouse $T b x 1$ to $Z d h h c 8$, and to zebrafish $t b x 1$ to tango2; Fig. 2). 22q11.2 region gene homologues were dispersed across 8 of the 25 zebrafish chromosome pairs, with the largest clusters involving chromosomes 5 and 8. 22q11.2 region homologues are distributed across all five fruit fly chromosomes, and all five autosomal worm chromosome pairs (Fig. 2).

No miRNAs were conserved in the zebrafish, fruit fly, or worm. The two miRNA conserved in the mouse were MIR185 and MIR1306. Human non-coding genes $(n=9)$, a read-through transcript, and pseudogenes $(n=27)$ in the 22q11.2 deletion region were not investigated in the model organisms studied.

\section{Availability of knockout and knockdown models of 22q11.2 region homologues in model organisms}

The high proportion of conserved protein-coding genes and their arrangement in the mouse has permitted the construction of contiguous multi-gene deletion models. These include several short and long deletion models, as previously reviewed [34, 35]. Of the 40 homologous genes in the mouse, 31 (77.5 \%) had available homozygous knockouts (Table 1). Notably, no mouse knockdown models were identified.

In zebrafish, of the 32 protein-coding conserved genes that did not have multiple putative homologues (i.e., excluding PRODH, SLC25A1, CLDN5, SEPT5, and COMT), ten $(31.3 \%)$ genes had knockouts and six (18.8 \%) had knockdowns; one (3.1\%; TBX1) had both available (Table 1). Neither knockouts nor knockdowns were available for a substantial proportion ( $n=15,46.9 \%)$ of these 32 genes. In the fruit fly, of the 22 protein-coding conserved genes, the majority $(n=19,86.4 \%)$ had both knockout and knockdown models available, two had only a knockout (9.1\%), and one had only a knockdown (4.5\%). In the worm, of the 17 protein-coding conserved genes, nearly half $(n=8$, $47.0 \%)$ had knockdowns available, and nine (53.0 \%) had both knockdowns and knockouts (Table 2).

\section{Availability of phenotypic information for conserved $22 q 11.2$ region genes in animal models}

Examination of the 17 genes conserved across species showed substantial variability in the availability and comprehensiveness of phenotypic information for homozygous and heterozygous knockouts, and knockdown models (Table 2). In the mouse, there were 13 genes with mutants available, of which nine had some form of phenotypic characterization. Zebrafish also appeared to be under-investigated; of 12 conserved genes with mutants available, phenotypic information was available for only six. Notably, a DGCR8 knockout has not been phenotypically assessed in zebrafish. More phenotypic information was available for mutants in the fruit fly (13 of 17 genes) and worm (15 genes), possibly due to the use of forward genetic screens in these organisms $[47,48]$. Only six genes were phenotypically characterized across all three of the simple model species (SLC25A1, UFD1L, TBX1, MED15, PI4KA, and SNAP29). Findings from these phenotypic studies are discussed below in the context of clinical manifestations of 22q11.2DS. We note that, as for all genetic studies, it is important to determine whether phenotypic effects are related to a specific background strain. This is an important consideration for all model animals including the mouse [49], zebrafish [50], fruit fly [51], and worm [52]. For example, Prodh homozygous in mice mutants were shown to be defective in prepulse inhibition [53], but this effect was dependent on genetic background [54].

\section{Discussion}

Here, we defined a comprehensive gene map of the most common human micro-deletion syndrome, 22q11.2DS, and conducted the first systematic examination of $22 \mathrm{q} 11.2$ deletion region gene conservation in simple model organisms. We developed a comprehensive resource of available knockout and knockdown models of conserved 22q11.2 
Table 2 Phenotype of available knockout/knockdown models for highly conserved 22q11.2 deletion region genes $(n=17)$

\begin{tabular}{|c|c|c|c|c|c|c|c|c|}
\hline \multirow[b]{2}{*}{ Gene $^{b}$} & \multicolumn{4}{|c|}{ Lethality (Knockout models) $)^{a}$} & \multicolumn{4}{|c|}{ Knockout and knockdown phenotypes } \\
\hline & C. elegans & $\begin{array}{l}\text { D. } \\
\text { melanogaster }\end{array}$ & D. rerio & $\begin{array}{l}\text { M. } \\
\text { musculus }\end{array}$ & C. elegans & D. melanogaster & D. rerio & M. musculus \\
\hline PRODH & - & No (KO) & $\begin{array}{l}\text { Not assessed } \\
\text { (KO, prodha); - } \\
\text { (LOC100537991) }\end{array}$ & No $(K O)$ & $\begin{array}{l}\text { Reduced accumulation rate of } \\
\text { newly synthesized proteins, } \\
\text { extended life span, increased } \\
\text { thermo-tolerance (KD) }\end{array}$ & $\begin{array}{l}\text { Hyperprolinemia, locomotor } \\
\text { defects including indecisive } \\
\text { movement patterns and } \\
\text { hypoactivity (KO); Not assessed } \\
\text { (KD) }\end{array}$ & $\begin{array}{l}\text { Not assessed (KO, prodha); - } \\
(\text { LOC100537991) }\end{array}$ & $\begin{array}{l}\text { Reduced male body weight and } \\
\text { prepulse inhibition (genetic } \\
\text { background dependent), impaired } \\
\text { fear conditioning, regionally altered } \\
\text { levels of proline (hyperprolinemia), } \\
\text { glutamate, gamma-aminobutyric } \\
\text { acid, and aspartate in the brain (KO) }\end{array}$ \\
\hline DGCR14 & $\begin{array}{l}\text { Embryonic } \\
\text { lethality } \\
\text { (KO); No } \\
\text { (het-KO) }\end{array}$ & - & - & $\begin{array}{l}\text { Not } \\
\text { assessed } \\
(\mathrm{KO})\end{array}$ & $\begin{array}{l}\text { Higher frequency of male } \\
\text { progeny, meiotic prophase } \\
\text { defect (KD); Deregulated mRNA } \\
\text { processing (KO); Normal } \\
\text { phenotype (het-KO) }\end{array}$ & Not assessed (KD) & - & Not assessed (KO) \\
\hline$S \angle C 25 A 1$ & - & $\begin{array}{l}\text { Embryonic } \\
\text { lethality (KO) }\end{array}$ & $\begin{array}{l}-(s / c 25 a 1 a, \\
\operatorname{sic} 25 a 1 b)\end{array}$ & $\begin{array}{l}\text { Majority } \\
\text { die before } \\
12 \text { weeks } \\
\text { post-natal } \\
\text { (KO) }\end{array}$ & $\begin{array}{l}\text { Normal when assessed for } \\
\text { lethality, sterility, anatomical } \\
\text { morphology, development, and } \\
\text { growth (KD) }\end{array}$ & $\begin{array}{l}\text { Chromosomal breaks and global } \\
\text { loss of DNA acetylation (KO) }\end{array}$ & $\begin{array}{l}\text { Mitochondrial depletion, flattened } \\
\text { head, small heart, brain, inner ear, } \\
\text { intestine, and mandibular arch } \\
\text { skeleton with defect severity } \\
\text { proportional to gene suppression, } \\
\text { neuromuscular junction defects } \\
\text { regardless of phenotype severity } \\
(\mathrm{KD}, \text { slc25a1a); Not assessed } \\
(\text { slc25a1b) }\end{array}$ & $\begin{array}{l}\text { Mice examined at two weeks are } \\
\text { small and sickly, and show } \\
\text { generalized hypoplasia, most } \\
\text { severely in liver and bone } \\
\text { marrow (KO) }\end{array}$ \\
\hline HIRA & $\begin{array}{l}\text { Embryonic } \\
\text { lethality } \\
\text { (KO) }\end{array}$ & $\begin{array}{l}\text { Embryonic } \\
\text { lethality }(\mathrm{KO})\end{array}$ & - & $\begin{array}{l}\text { Embryonic } \\
\text { lethality } \\
(\mathrm{KO}) \text {; No } \\
\text { (het-KO) }\end{array}$ & Not assessed (KO, KD) & $\begin{array}{l}\text { Enhanced transcriptional } \\
\text { suppression through variegation } \\
\text { with transposable element } \\
\text { probe, offspring of null mothers } \\
\text { crossed with wild-type males do } \\
\text { not develop while paternal null } \\
\text { offspring show only partial le- } \\
\text { thality implying maternal effect } \\
\text { (KO); Not assessed (KD) }\end{array}$ & Not assessed (KD) & $\begin{array}{l}\text { Disrupted gastrulation, abnormal } \\
\text { cardiac development (e.g., heart } \\
\text { chambers), abnormal embryonic } \\
\text { tissue morphology, abnormal } \\
\text { placenta, craniofacial abnormalities, } \\
\text { failure of brain to fuse and } \\
\text { abnormal neural plate morphology } \\
\text { (KO); Decreased leukocyte cell } \\
\text { count (het-KO) }\end{array}$ \\
\hline MRPL40 & - & $\begin{array}{l}\text { Embryonic } \\
\text { lethality (KO) }\end{array}$ & - & $\begin{array}{l}\text { Not } \\
\text { assessed } \\
\text { (KO) }\end{array}$ & $\begin{array}{l}\text { Slow growth, larval arrest, } \\
\text { reduced brood size, sterile } \\
\text { progeny (KD) }\end{array}$ & $\begin{array}{l}\text { Gross neuroanatomical defects } \\
\text { due to under-proliferation of } \\
\text { neuroblast cells during neuro- } \\
\text { genesis (KO); Not assessed (KD) }\end{array}$ & - & Not assessed (KO) \\
\hline UFD1L & - & No (KO) & $\begin{array}{l}\text { Embryonic } \\
\text { lethality }(\mathrm{KO})\end{array}$ & $\begin{array}{l}\text { Not } \\
\text { assessed } \\
\text { (KO); No } \\
\text { (het-KO) }\end{array}$ & $\begin{array}{l}\text { Slow growth, gonad development } \\
\text { deficits, enlarged gut granules, } \\
\text { locomotor defect with deviations } \\
\text { in self-propelled movement, } \\
\text { patchy coloration, reduced life } \\
\text { span (KD) }\end{array}$ & $\begin{array}{l}\text { Stress response reduced as } \\
\text { determined by virus infection } \\
\text { assay (KO); Not assessed (KD) }\end{array}$ & $\begin{array}{l}\text { Decreased eye size, abnormal } \\
\text { head shape due to hypoplasia } \\
\text { and misarranged features, } \\
\text { necrotic central nervous system, } \\
\text { increased thickness of } \\
\text { mandibular arch skeleton, } \\
\text { hypoplastic gut and liver (KO) }\end{array}$ & $\begin{array}{l}\text { Not assessed (KO); Viable with no } \\
\text { obvious heart defects (het-KO) }\end{array}$ \\
\hline$C D C 45$ & $\begin{array}{l}\text { Embryonic } \\
\text { lethality } \\
\text { (KO) }\end{array}$ & $\begin{array}{l}\text { Lethal in the } \\
\text { larval stage } \\
\text { (KO) }\end{array}$ & $\begin{array}{l}\text { Not assessed } \\
(\mathrm{KO})\end{array}$ & $\begin{array}{l}\text { Embryonic } \\
\text { lethality } \\
\text { (KO); No } \\
\text { (het-KO) }\end{array}$ & $\begin{array}{l}\text { Everted vulva, reduced brood } \\
\text { size, sterility associated with no } \\
\text { sperm development (KO); Sister } \\
\text { chromatid segregation defective } \\
\text { in early embryo, reduced brood } \\
\text { size (KD) }\end{array}$ & $\begin{array}{l}\text { Gross neuroanatomy defective } \\
\text { due to reduced cellular } \\
\text { proliferation causing small } \\
\text { neuroblast size in the } \\
\text { developing brain (KO); Not } \\
\text { assessed (KD) }\end{array}$ & Not assessed (KO) & $\begin{array}{l}\text { Impaired proliferation of inner cell } \\
\text { mass after embryo implantation } \\
\text { (KO); Normal when assessed for } \\
\text { size, behaviour, and sterility } \\
\text { (het-KO) }\end{array}$ \\
\hline
\end{tabular}


Table 2 Phenotype of available knockout/knockdown models for highly conserved 22q11.2 deletion region genes ( $n=17$ ) (Continued)

\begin{tabular}{|c|c|c|c|c|c|c|c|c|}
\hline \multirow[b]{2}{*}{ Gene $^{a}$} & \multicolumn{4}{|c|}{ Lethality (Knockout models) } & \multicolumn{4}{|c|}{ Knockout and knockdown phenotypes } \\
\hline & C. elegans & $\begin{array}{l}\text { D. } \\
\text { melanogaster }\end{array}$ & D. rerio & $\begin{array}{l}\text { M. } \\
\text { musculus }\end{array}$ & C. elegans & D. melanogaster & D. rerio & M. musculus \\
\hline TBX1 & No (KO) & $\begin{array}{l}\text { Partial } \\
\text { embryonic } \\
\text { lethality }(\mathrm{KO})\end{array}$ & $\begin{array}{l}\text { Embryonic } \\
\text { lethality }(\mathrm{KO})\end{array}$ & $\begin{array}{l}\text { Embryonic } \\
\text { lethality } \\
\text { (KO); No } \\
\text { (het-KO) }\end{array}$ & $\begin{array}{l}\text { Abnormal uterine cell fate due to } \\
\text { transcriptional abnormalities (KO); } \\
\text { Normal when assessed for } \\
\text { sterility, anatomical morphology, } \\
\text { and development (KD) }\end{array}$ & $\begin{array}{l}\text { Severely malformed or absent } \\
\text { adult muscle precursors and } \\
\text { supportive alary heart muscles } \\
\text { (KO); Not assessed (KD) }\end{array}$ & $\begin{array}{l}\text { Severely abnormal cardiac } \\
\text { development (e.g., absent aortic } \\
\text { arch), severe pouch defects and } \\
\text { abnormal facial skeletal } \\
\text { development, abnormal inner } \\
\text { ear morphology (KO); Severely } \\
\text { abnormal cardiac development } \\
\text { (e.g., absent aortic arches) and } \\
\text { thymus (KD) }\end{array}$ & $\begin{array}{l}\text { Severely abnormal cardiac } \\
\text { development (e.g., aortic arch), } \\
\text { abnormal inner, middle, and } \\
\text { outer ear morphology, abnormal } \\
\text { lymphangiogenesis, abnormal } \\
\text { cranial base morphology (KO); } \\
\text { Mild cardiac abnormalities (e.g., } \\
\text { fourth aortic arch arteries) and } \\
\text { decreased prepulse inhibition } \\
\text { (het-KO) }\end{array}$ \\
\hline TXNRD2 & - & - & - & $\begin{array}{l}\text { Embryonic } \\
\text { lethality } \\
\text { (KO) }\end{array}$ & $\begin{array}{l}\text { Hypersensitive to protein } \\
\text { aggregation induced paralysis } \\
\text { (KD) but otherwise normal when } \\
\text { assessed for morphology and } \\
\text { development (KO, KD) }\end{array}$ & Not assessed (KD) & - & $\begin{array}{l}\text { Severe anemia and growth } \\
\text { retardation due to perturbed } \\
\text { cardiac development and } \\
\text { augmented apoptosis of } \\
\text { hematopoietic cells (KO) }\end{array}$ \\
\hline TANGO2 & - & $\begin{array}{l}\text { Not assessed } \\
(\mathrm{KO})\end{array}$ & $\begin{array}{l}\text { Not assessed } \\
(\mathrm{KO})\end{array}$ & - & Not assessed (KD) & Not assessed $(\mathrm{KO}, \mathrm{KD})$ & - & - \\
\hline$D G C R 8$ & No $(\mathrm{KO})$ & $\begin{array}{l}\text { Lethal } \\
\text { before end } \\
\text { of pupal } \\
\text { stage }(\mathrm{KO})\end{array}$ & $\begin{array}{l}\text { Not assessed } \\
(\mathrm{KO})\end{array}$ & $\begin{array}{l}\text { Embryonic } \\
\text { lethality } \\
\text { (KO); No } \\
\text { (het-KO) }\end{array}$ & $\begin{array}{l}\text { Accumulation of miRNA target } \\
\text { protein, decreased lifespan (KO); } \\
\text { Reduced miRNA processing, } \\
\text { accumulation of target mRNA, } \\
\text { vulva defects, enhanced } \\
\text { locomotor deficits of unc } \\
\text { mutant (uncoordinated) } \\
\text { phenotypes (KD) }\end{array}$ & $\begin{array}{l}\text { Abnormal olfactory projection and } \\
\text { mushroom body neuron } \\
\text { morphology and neurophysiology } \\
\text { (KO); Not assessed (KD) }\end{array}$ & Not assessed (KO) & $\begin{array}{l}\text { Reduced dendritic spine } \\
\text { number, reduced dendritic } \\
\text { complexity, decreased prepulse } \\
\text { inhibition and abnormal spatial } \\
\text { working memory (het-KO) }\end{array}$ \\
\hline TRMT2A & No (KD) & No $(\mathrm{KO})$ & $\begin{array}{l}\text { Not assessed } \\
(\mathrm{KO})\end{array}$ & $\begin{array}{l}\text { Not } \\
\text { assessed } \\
(\mathrm{KO})\end{array}$ & $\begin{array}{l}\text { Not maternally sterile but } \\
\text { otherwise not assessed (KD) }\end{array}$ & $\begin{array}{l}\text { Not sterile (KO); Not assessed } \\
\text { (KD) }\end{array}$ & Not assessed (KO) & Not assessed (KO) \\
\hline MED15 & $\begin{array}{l}\text { Reduced } \\
\text { lifespan } \\
\text { (KO) }\end{array}$ & $\begin{array}{l}\text { Pupal } \\
\text { lethality (KO) }\end{array}$ & - & - & $\begin{array}{l}\text { Sterile, small, increased apoptosis, } \\
\text { decreased protein expression, } \\
\text { changes in mRNA expression, } \\
\text { intestinal morphology, reduced } \\
\text { lifespan, uncoordinated } \\
\text { locomotion (KD); Hypersensitivity } \\
\text { to toxin exposure (KO, KD) }\end{array}$ & $\begin{array}{l}\text { Abnormal wing development } \\
(\mathrm{KO}, \text { het-KO); Abnormal wing } \\
\text { development and shortened } \\
\text { legs, formation of ectopic } \\
\text { sensory organs and induced } \\
\text { cellular apoptosis (KD) }\end{array}$ & $\begin{array}{l}\text { Disruption of dorsal/ventral } \\
\text { patterning and mesoderm } \\
\text { development (KD) }\end{array}$ & - \\
\hline PISKA & $\begin{array}{l}\text { Embryonic } \\
\text { lethality } \\
(\mathrm{KO})\end{array}$ & $\begin{array}{l}\text { Lethal } \\
\text { before end } \\
\text { of larval } \\
\text { stage }(\mathrm{KO})\end{array}$ & - & $\begin{array}{l}\text { Embryonic } \\
\text { lethality } \\
(\mathrm{KO})\end{array}$ & Slow growth and sterility (KD) & $\begin{array}{l}\text { Abnormal eye morphology, } \\
\text { neuromuscular junction } \\
\text { overgrowth (KO); Not assessed } \\
\text { (KD) }\end{array}$ & $\begin{array}{l}\text { Decreased eye, head, and } \\
\text { mesenchymal cell proliferation, } \\
\text { increased apoptosis and necrosis } \\
\text { of brain cells }(\mathrm{KD})\end{array}$ & $\begin{array}{l}\text { Premature death due to } \\
\text { degeneration of mucosal cells in } \\
\text { the stomach and intestines (KO) }\end{array}$ \\
\hline SNAP29 & $\begin{array}{l}\text { Embryonic } \\
\text { lethality } \\
\text { (KO) }\end{array}$ & $\begin{array}{l}\text { Pupal } \\
\text { lethality (KO) }\end{array}$ & - & $\begin{array}{l}\text { Pre- } \\
\text { weaning } \\
\text { lethality } \\
\text { (KO) }\end{array}$ & $\begin{array}{l}\text { Defects in secretion from intestinal } \\
\text { epithelial cells (KO); Sterility } \\
\text { associated with endomitotic } \\
\text { oocytes and pre-mitotic maturation } \\
\text { of the oocyte, abnormal localization } \\
\text { of phospholipid membrane } \\
\text { components (KD) }\end{array}$ & $\begin{array}{l}\text { Not assessed (KO); Synaptic } \\
\text { defects characterized by abnormal } \\
\text { basal neurotransmission. Lethality } \\
\text { observed in the pupal stage (KD) }\end{array}$ & $\begin{array}{l}\text { Disrupted pigmentation, } \\
\text { epidermal irregular spatial } \\
\text { pattern, disorganized } \\
\text { keratinocyte cell surface (KD) }\end{array}$ & Not assessed (KO) \\
\hline
\end{tabular}


Table 2 Phenotype of available knockout/knockdown models for highly conserved 22q11.2 deletion region genes $(n=17)$ (Continued)

\begin{tabular}{|c|c|c|c|c|c|c|c|c|}
\hline \multicolumn{2}{|l|}{$\overline{\text { AIFM3 }}$} & No $(\mathrm{KO})$ & - & - & $\begin{array}{l}\text { Normal when assessed for } \\
\text { lifespan and sterility, anatomical } \\
\text { morphology, development, and } \\
\text { growth (KD) }\end{array}$ & $\begin{array}{l}\text { Not sterile (KO); Not assessed } \\
\text { (KD) }\end{array}$ & - & - \\
\hline SLC7A4 & - & $\begin{array}{l}\text { Not assessed } \\
(\mathrm{KO})\end{array}$ & $\begin{array}{l}\text { Not assessed } \\
(\mathrm{KO})\end{array}$ & - & $\begin{array}{l}\text { Normal when assessed for } \\
\text { sterility and anatomical } \\
\text { morphology }(\mathrm{KD})\end{array}$ & Not assessed (KO, KD) & Not assessed (KO) & - \\
\hline
\end{tabular}

${ }^{2}$ Knockout (KO) indicates homozygous KO model phenotype; except where indicated as a heterozygous KO (het-KO) phenotype

${ }^{\mathrm{b}}$ Genes ordered by proximal to distal 22q11.2 locus position; "-" indicates no knockout (KO) or knockdown (KD) model available. Lethality for KD models is not included as this may vary based on when the gene is suppressed 
region homologues. Our results demonstrate that of the human 22q11.2 region protein-coding genes, a substantial proportion is conserved in simple model organisms. These mutant model organisms are amenable to extensive phenotypic characterization. This novel comparative multi-species resource can be used to provide initial insights into how simple animal models could be used to investigate the multi-system congenital and neurodevelopmental conditions associated with hemizygous 22q11.2 deletions.

\section{Advantages of using a non-murine animal model in the study of 22q11.2DS}

The amenability of the zebrafish, fruit fly, and worm to genetic manipulation compared with the mouse could facilitate rapid and cost-effective generation of individual targeted gene and multi-gene mutations (Table 1). Such manipulations will be essential to functional studies and gene variant interpretation of 22q11.2 region genes. Moreover, the ease of genetic manipulation could rapidly improve our understanding of how the 22q11.2 deletion may interact with the rest of the genome to mediate the variable expressivity of 22q11.2DS associated phenotypes through mechanisms such as translational modifications due to the loss of one copy of DGCR8 and 22q11.2 region miRNA genes [55]. The relatively high proportion of 22q11.2 deletion region gene knockouts available in the mouse compared with the zebrafish and the worm is notable given that the process of developing knockout mouse models is expensive and time-consuming, calculated to take on average of about 1 year at a cost of more than US $\$ 12,000$ [56]. With the advent of the CRISPR/ Cas9 system, the cost and speed of developing knockouts for all organisms will substantially decrease [57].

Unlike the mouse, knockdown models for 22q11.2DS homologues are available for the zebrafish, fruit fly, and worm (Table 1). Gene knockdown technologies are advantageous because they can be used to reduce gene expression in a dose-dependent manner with a high degree of specificity [58, 59], essential for examining 22q11.2DS, where dose-dependency is thought to underlie phenotypic changes [15]. All knockdowns found for 22q11.2 homologues in the zebrafish were generated using morpholinos [60]. Knockdowns in the worm and fruit fly commonly employed RNA interference (RNAi) methods. Notably, it is possible to knockdown two genes simultaneously using combinatorial RNAi in C. elegans and D. melanogaster [61, 62]. There are, as yet, no examples of this for $22 \mathrm{q} 11.2$ region genes, although such experiments could yield critical insights into the possibility of epistatic effects between 22q11.2 region genes that may mediate the complex expression of 22q11.2DS associated phenotypes [54]. Although RNAi technology is available in some vertebrates including the mouse, it is rarely used due to the length of
RNAi generation times and the lack of simplicity compared with invertebrates [58].

\section{Suitability of non-murine model organisms to study 22q11.2DS}

Useful and valid model organisms should demonstrate examples of convergence with the human 22q11.2DS phenotype, thus providing proof-of-principle of the utility of these organisms in characterizing gene function and disease modeling (e.g., as we observed here for TBX1). Cellular and phenotypic observations already made in lower animals could identify new avenues of investigation regarding the roles of particular genes in different 22q11.2DS phenotypes. The limited data available make it difficult at present to make phenotypic comparisons between species that could help to indicate conserved molecular functions of 22q11.2 genes, especially as such data were rarely collected in the context of 22q11.2DS (Table 2). However the data reveal opportunities for novel functional studies of these genes.

One example of particular relevance to neurodevelopmental processes comes from $P R O D H$, which encodes a mitochondrial enzyme that metabolizes L-proline [63], an amino acid involved in modulating glutamatergic and GABA-ergic transmission [64]. A report of severe psychomotor delay in a male with a homozygous deletion [65] indicates $P R O D H$ may also be an important candidate gene for motor functioning. Movement abnormalities are commonly observed in individuals with 22q11.2DS, including hypotonia in infancy, delayed gross-motor milestones in childhood [66], susceptibility to antipsychotic-induced movement disorders [67], and early-onset Parkinson's disease [13], but it remains unclear which of the 22q11.2 genes are involved in these processes. Observations in the fruit fly, however, suggest a novel role for $P R O D H$ in motor pathways (Table 2). Its $P R O D H$ homologue, $\operatorname{sg} A$, is prominently expressed in the nervous system during embryonic development and shows proline dehydrogenase activity [63]. Fruit flies with a homozygous $P R O D H$ mutation demonstrate severe locomotor defects and indecisive movement patterns compared with wild-type flies in an activity chamber assay [63]. Notably, this observation in the fruit fly spurred the study of Prodh in locomotion in mouse models, where the effects of Prodh have been less clear [53, 54]. Further study on the role of $P R O D H$ in mediating 22q11.2DS associated motor deficits is warranted.

Gene knockout or knockdown technologies have only recently been used in non-mouse model organisms, specifically in the context of 22q11.2DS phenotypes. One of the few examples is $S L C 25 \mathrm{Al}$, a mitochondrial citrate transporter important for proper mitochondrial functioning. In zebrafish, knockdown of the SLC25A1 homologue, slc25a1a, during embryonic development causes mitochondrial depletion and gross morphological defects that 
recapitulate some features of 22q11.2DS (Table 2). Zebrafish treated with a slc25a1a morpholino showed a dosedependent phenotype, with higher doses leading to more severe developmental dysmorphic abnormalities such as a flattened head and a marked reduction in the size of the entire cranial region, including the brain [68]. Additionally, fish with marked slc25a1a depletion had small hearts surrounded by pericardial edema. These results indicate that slc25a1a plays a role in cardiac as well as craniofacial and brain development, all cardinal features of 22q11.2DS. Notably, these phenotypes were rescued in treated animals when autophagy was blocked [68]. SLC25A1 exemplifies the potential for studies using knockdown models of simpler organisms to investigate the molecular underpinning of 22q11.2DS phenotypes that may yield novel therapeutic targets.

A novel avenue of investigation based on the high degree of gene conservation of mitochondrial genes in the 22q11.2DS region is also now indicated. Mitochondrial dysfunction is implicated in the etiology of brain-based disorders associated with 22q11.2DS, including developmental delay, schizophrenia, and Parkinson's disease [69-71], and perturbation of mitochondria and related pathways affects key cellular processes such as cell migration, apoptosis, and synapse formation [72]. Aberrant expression of mitochondrial genes, already documented in 22q11.2DS patients for five of the six (PRODH remains unexamined) 22q11.2 mitochondrial genes [73], all found in the human brain (Fig. 1), could mediate susceptibility to neurological conditions in individuals with 22q11.2DS. For example, MRPL40 knockouts in the fruit fly show defects in neurogenesis that compromise neurodevelopment (Table 2), and knockdowns of TXNRD2 in worms overexpressing human beta-amyloid peptide as a model for Alzheimer's disease were more susceptible to muscular dysfunction and paralysis [74]. More comprehensive studies of neurodevelopment and neurodegeneration in lower organisms could shed light on the molecular function of these critical proteins.

\section{Individual organism suitability for studying specific 22q11.2DS phenotypes}

Like the mouse [34, 35], zebrafish, fruit fly, and worm models are unable to singularly recapitulate all of the 22q11.2DS associated phenotypes. A limitation for all animal models is the challenge presented by complex disease phenotypes, such as the range of psychiatric disorders associated with 22q11.2DS. Particularly for simple organisms, limited behaviors, and the paucity of reproducible tests make it difficult to study such phenotypes. Although a considerable number of genes are conserved in the zebrafish, fruit fly, and worm, incomplete conservation limits the ability to fully investigate the roles and possible interactions between all 22q11.2 region genes.
However, these issues should not discourage the further study of specific 22q11.2DS orthologs. As discussed below for each proposed model organism, orthologs in lower animals could be very useful for clarifying the roles of 22q11.2 deletion region genes in basic neurodevelopmental trajectories (e.g. development of neuronal components), as well as organ development. For example, despite the absence of a heart in the worm, mutants of $m l s-1$ (the ortholog of TBX1) indicate that $m l s-1$ is involved in the specification of non-striated muscle during development [75], suggesting the potential utility for these mutants in studying how TBX1 mediates heart development in higher organisms. Discretion is essential when deciding which model organism to use to study particular 22q11.2DS phenotypes. However, organismspecific characteristics and developmental trajectories do suggest that certain 22q11.2DS phenotypes are particularly well suited for study in each of these non-mouse models.

Congenital cardiac defects, involving cardiovascular molecular development, are major manifestations of 22q11.2DS [3] where the molecular underpinnings are difficult to analyze in mammalian models, since there is rapid death without an intact cardiovascular system during embryonic development [76]. Improvements in generating conditional gene deletion models using technologies such as the Cre-loxP and Tet-On/Tet-Off system in mice offer the potential to circumvent these issues, but have not been fully developed in the context of investigating congenital heart defects [77, 78]. Recently, the zebrafish has emerged as a highly advantageous vertebrate model for studying early cardiovascular development, largely due to the ability of the zebrafish embryos to obtain oxygen in the absence of blood circulation through passive diffusion. 1This permits survival of the initial stages of embryonic development and allows investigation of even severe cardiovascular defects [79]. The additional optical transparency of zebrafish embryos, used in combination with tissue-specific expression of fluorescent proteins, permits visualization of early molecular processes [80]. In humans, $T B X 1$ is associated with heart defects, palatal anomalies, facial dysmorphism, and low calcium levels [81, 82] albeit each with reduced penetrance [3]. In the zebrafish, inhibiting the TBX1 homologue leads to developmental defects of the pharyngeal arches, aortic arches, and thymus (Table 2). Abnormal cardiac morphology was visible in roughly $20 \%$ of knockdowns, with compromised cardiac performance in nearly all injected embryos [83]. The zebrafish provides a unique opportunity to study early development and how 22q11.2 gene dosage affects these processes through the use of knockdown technologies.

The fruit fly is particularly well-suited for the study of the myriad brain-related disorders associated with 22q11.2DS $[3,6,9,13,84]$, including intellectual disability, and other 
neurodevelopmental [85] and neurodegenerative disorders [86]. The benefits of using D. melanogaster include its short generation time along with a high reproductive rate and the availability of powerful genetic and molecular tools. Genes of interest can be readily manipulated in a time and cell-or tissue-specific manner using well-established tools such as the GAL4/UAS-system [86]. Together with well-characterized developmental stages, a simple and defined nervous system, and the ability to conduct large-scale behavioral and neurophysiological assays, the fruit fly has proven a valuable tool in the study of genomic and neurological disorders [87]. Similar opportunities for study are possible for 22q11.2DS, although there have been few studies to date targeted to 22q11.2DS (Table 2). Nevertheless, studies in the fruit fly have already provided some novel insights into the molecular function of 22q11.2 deletion region genes pertinent to the associated neurological conditions. For example, in the context of identifying novel intellectual disability candidate genes in a large-scale screening study, flies with a knockdown of SNAP29 were found to have profound synaptic defects characterized by abnormal basal neurotransmission [88] (Table 2).

To better assess the role of 22q11.2DS genes in developmental processes, additional molecular information is needed, such as where and when a gene is expressed, and elucidation of its protein-protein interactions. An ideal model for these experiments is the worm. In addition to having conserved fundamental biological processes and homology with mammals, the worm is noteworthy for being highly amenable to forward and reverse genetic screens $[89,90]$. One 22q11.2DS gene provides an example of the utility of using the worm system to study 22q11.2DS is DGCR8, a component of the "microprocessor" complex essential for genome-wide miRNA production [91] that may mediate the expression of multiple 22q11.2DS associated phenotypes in patients, including schizophrenia [41-43]. In mice, Dgcr8 has been implicated in altering the biogenesis of genome-wide brain miRNA [92]. Indeed, miRNAs were first discovered in 1993 in genetic screens performed in the worm and were initially thought to be phenomena unique to nematode biology [93, 94]. It was later found that miRNA are widely conserved among eukaryotes as functional non-coding RNAs [95] and their role has been further studied in the mouse [96], zebrafish [97], and fruit fly [98].

DGCR8 was first identified as a candidate gene for miRNA processing based on a genome-wide two-hybrid analysis of $D$. melanogaster where the protein product, Pasha, was shown to interact with Drosha $[99,100]$. Inactivation of a temperature sensitive allele of DGCR8 in C. elegans lead to the accumulation of protein products of other genes elsewhere in the genome, particularly let-7, and a reduction in life span [101]. Similar mechanisms could be associated with the unexplained premature mortality reported in individuals with 22q11.2 DS [102]. In another study investigating gene-gene interaction mechanisms, RNAi targeting the worm DGCR8 homologue resulted in exacerbation of the uncoordinated motor phenotype caused either by a mutation in the human tau-FTDP-17 homologue or by unc (uncoordinated) mutations [103]. This is of interest in light of motor defects seen in patients with 22q11.2DS [104, 105]. Comparable interactive mechanisms, involving effects of hemizygosity of DGCR8 on expression of mRNA across the genome, may also be operating in 22q11.2DS [41-43]. Differences in mRNA expression may also be mediated by another 22q11.2 region gene, DGCR14, whose ortholog in C. elegans has been implicated in promoting proper mRNA splicing when splice sites are compromised [106]. Notably, conservation is a key means of determining relevance of a non-proteincoding sequence in humans [107].

Another as yet unexplored area in the context of model organisms and 22q11.2DS relates to the development of pharmaceutical agents to treat 22q11.2DS related phenotypes. Collectively, D. rerio, D. melanogaster, and C. elegans are particularly suited to screening chemical libraries for potential drug development, circumventing the high financial and time investment for M. musculus [108].

\section{Study limitations}

We used a reciprocal best hits method to identify putative orthologs of human 22q11.2 genes in simple model organisms, a common and well-established method to probe orthology based on sequence similarity [39]. In this exploratory study, we did not restrict to a minimum sequence identity in order to identify all putative orthologs of the human 22q11.2 genes. Similarity in protein sequences does not necessarily translate to conserved function or patterns of gene expression across species. Further experiments are needed to assay possible conserved functional roles $[109,110]$ of the homologues identified here. Importantly, we found that our results were consistent with previous homology relationships described for 22q11.2DS genes (e.g., PRODH [111], UFD1L [112], DGCR6 [113], MED15 [114], TSSK2 [115], and TXNRD2 [116]). Using these methods, we identified multiple putative homologues for individual 22q11.2 deletion region genes in the zebrafish, possibly related to gene duplication [45]. In these cases, functional studies are required to examine which homologue may have a conserved function. Additionally, using the stringent criteria for the reciprocal best hits method, homology may be difficult to establish for genetically distant species. For example, query coverage was too low to identify a reciprocal best hit for the mitochondrial gene $Z D H H C 8$ in the fruit fly and worm. Our analyses were restricted to protein-coding genes and miRNAs. The examination of other non-coding genes will be 
deferred due to the limited resources available as of yet. For the 17 genes conserved across all species examined, we noted some discrepancies in mutant phenotypes across species that could suggest divergent gene functions (Table 2). However, this is likely related to the absence of studies of comparable phenotypes (e.g., the cardiovascular system investigated in one organism but not another) and the relative sparseness of available data for many genes.

\section{Conclusions}

These results indicate that the zebrafish, fruit fly, and worm are valuable but underused model organisms in the study of the important human genetic syndrome, 22q11.2DS, associated with a 22q11.2 deletion involving 46 protein-coding genes. There is a relatively high degree of conservation of these genes, and some relevant models already exist in non-murine organisms. Despite this, few have been studied in the context of 22q11.2DS. Manipulating expression of 22q11.2 region genes in the zebrafish, fruit fly, or worm can reveal phenotypic manifestations relevant to 22q11.2DS and a greater understanding of their molecular origins in ways that are not possible in humans or readily possible in mouse models. In addition to providing a novel comprehensive comparative resource for the many developmental genes in the 22q11.2 region, we illustrate a proof-of-principle of the utility for applying a similar approach to investigating other pathogenic copy number variants associated with multi-system developmental disorders and important neurodevelopmental phenotypes.

\section{Additional file}

Additional file 1: 22q11.2 gene homologue locations. The human 22q11.2DS deletion region genetic content and order was mapped from NCBI Gene Homo sapiens Annotation Release 105 using Affymetrix CytoScan HD (Santa Clara, CA, USA) array mean breakpoints (chr22:18,820,303-21,489,474) ascertained from 16 patients with confirmed 22q11.2 deletions. Protein Basic Local Alignment Search Tool (blastp) analysis on UniProtKB was used to identify putative homologues using the reciprocal best-hits method. NCBI was used to find gene coordinates of putative homologues. All data were recent to 2 December 2014. See Methods for additional details.

\section{Competing interests}

The authors declare that they have no competing interests.

\section{Authors' contributions}

AG contributed to the study conception and design, and performed data collection, data analysis and interpretation, and drafted the manuscript. NJB and ASB contributed to the conception of the study and design, interpretation of data, and helped draft the manuscript. All authors read and approved the final manuscript.

\section{Acknowledgements}

This work was supported by the Canadian Institutes of Health Research (ASB, MOP \#97800, MOP \#111238), Canada Research Chairs program and Dalglish Chair in 22q11.2 Deletion Syndrome (ASB), an Institute of Medical Science Summer Undergraduate Research Award (AG) and a Brain Canada Mental Health Training Award (NJB).

\section{Author details}

${ }^{1}$ Clinical Genetics Research Program and Campbell Family Mental Health Research Institute, Centre for Addiction and Mental Health, Toronto, ON, Canada. ${ }^{2}$ Institute of Medical Science, University of Toronto, Toronto, ON, Canada. ${ }^{3}$ Dalglish Family Hearts and Minds Clinic for Adults with 22q11.2 Deletion Syndrome, Division of Cardiology, Department of Medicine, Department of Psychiatry, and Toronto General Research Institute, University Health Network, Toronto, ON, Canada. ${ }^{4}$ Department of Psychiatry, University of Toronto, Toronto, ON, Canada. ${ }^{5}$ Centre for Addiction and Mental Health, 33 Russell Street, Room 1100, M5S 2S1 Toronto, ON, Canada.

Received: 23 February 2015 Accepted: 26 May 2015

Published online: 01 July 2015

\section{References}

1. Goodship J, Cross I, LiLing J, Wren C. A population study of chromosome 22q11 deletions in infancy. Arch Dis Child. 1998;79(4):348-51.

2. Bassett AS, McDonald-McGinn DM, Devriendt K, Digilio MC, Goldenberg P, Habel A, et al. Practical guidelines for managing patients with 22q11.2 deletion syndrome. J Pediatr. 2011;159(2):332-9. e1.

3. Bassett AS, Chow EW, Husted J, Weksberg R, Caluseriu O, Webb GD, et al. Clinical features of 78 adults with 22q11 deletion syndrome. Am J Med Genet A. 2005;138(4):307-13.

4. Fung WL, Chow EW, Webb GD, Gatzoulis MA, Bassett AS. Extracardiac features predicting 22q11.2 deletion syndrome in adult congenital heart disease. Int J Cardiol. 2008;131(1):51-8.

5. Fung WL, Butcher NJ, Costain G, Andrade DM, Boot E, Chow EW, et al. Practical guidelines for managing adults with 22q11.2 deletion syndrome. Genet Med. In press.

6. Niklasson L, Gillberg C. The neuropsychology of $22 q 11$ deletion syndrome. A neuropsychiatric study of 100 individuals. Res Dev Disabil. 2010;31(1):185-94.

7. Gothelf D, Presburger G, Levy D, Nahmani A, Burg M, Berant M, et al. Genetic, developmental, and physical factors associated with attention deficit hyperactivity disorder in patients with velocardiofacial syndrome. Am J Med Genet B Neuropsychiatr Genet. 2004;126B(1):116-21.

8. Young AS, Shashi V, Schoch K, Kwapil T, Hooper SR. Discordance in diagnoses and treatment of psychiatric disorders in children and adolescents with 22q11.2 deletion syndrome. Asian J Psychiatr. 2011;4(2):119-24.

9. Fung WL, McEvilly R, Fong J, Silversides C, Chow EW, Bassett AS. Elevated prevalence of generalized anxiety disorder in adults with 22q11.2 deletion syndrome. Am J Psychiatry. 2010;167(8):998.

10. Hidding E, Swaab $H$, de Sonneville LM, van Engeland H, Sijmens-Morcus ME, Klaassen PW, et al. Intellectual functioning in relation to autism and ADHD symptomatology in children and adolescents with 22q11.2 deletion syndrome. J Intellect Disabil Res. In press.

11. Vorstman JA, Morcus ME, Duijff SN, Klaassen PW, Heineman-de Boer JA, Beemer FA, et al. The 22q11.2 deletion in children: high rate of autistic disorders and early onset of psychotic symptoms. J Am Acad Child Adolesc Psychiatry. 2006;45(9):1104-13.

12. Bassett AS, Chow EW. Schizophrenia and 22q11.2 deletion syndrome. Curr Psychiatry Rep. 2008;10(2):148-57.

13. Butcher NJ, Kiehl TR, Hazrati LN, Chow EW, Rogaeva E, Lang AE, et al. Association between early-onset Parkinson disease and 22q11.2 deletion syndrome: identification of a novel genetic form of Parkinson disease and its clinical implications. JAMA Neurol. 2013;70(11):1359-66.

14. Booij J, van Amelsvoort T, Boot E. Co-occurrence of early-onset Parkinson disease and 22q11.2 deletion syndrome: potential role for dopamine transporter imaging. Am J Med Genet A. 2010;152A(11):2937-8.

15. Meechan DW, Maynard TM, Wu Y, Gopalakrishna D, Lieberman JA, LaMantia AS. Gene dosage in the developing and adult brain in a mouse model of 22q11 deletion syndrome. Mol Cell Neurosci. 2006;33(4):412-28.

16. Emanuel BS. Molecular mechanisms and diagnosis of chromosome $22 q 11.2$ rearrangements. Dev Disabil Res Rev. 2008;14(1):11-8.

17. Bassett AS, Marshall CR, Lionel AC, Chow EW, Scherer SW. Copy number variations and risk for schizophrenia in 22q11.2 deletion syndrome. Hum Mol Genet. 2008;17(24):4045-53.

18. Edelmann L, Pandita PK, Spiteri E, Funke B, Goldberg R, Palanisamy N, et al. A common molecular basis for rearrangement disorders on chromosome 22q11. Hum Mol Genet. 1999;8(7):1157-67. 
19. Shaikh TH, Kurahashi H, Saitta SC, O'Hare AM, Hu P, Roe BA, et al. Chromosome 22-specific low copy repeats and the 22q11.2 deletion syndrome: genomic organization and deletion endpoint analysis. Hum Mol Genet. 2000;9(4):489-501.

20. Baumer A, Dutly F, Balmer R, Riegel M, Tukel T, Krajewska-Walasek M, et al. High level of unequal meiotic crossovers at the origin of the 22q11. 2 and 7q11.23 deletions. Hum Mol Genet. 1998;7(5):887-94.

21. Saitta SC, Harris SE, Gaeth AP, Driscoll DA, McDonald-McGinn DM, Maisenbacher MK, et al. Aberrant interchromosomal exchanges are the predominant cause of the 22q11.2 deletion. Hum Mol Genet. 2004;13(4):417-28.

22. Carlson C, Paplos D, Pandita RK, Faedda GL, Veit S, Goldberg R, et al. Molecular analysis of velo-cardio-facial syndrome patients with psychiatric disorders. Am J Hum Genet. 1997;60(4):851-9.

23. Weksberg R, Stachon AC, Squire JA, Moldovan L, Bayani J, Meyn S, et al. Molecular characterization of deletion breakpoints in adults with 22 q11 deletion syndrome. Hum Genet. 2007;120(6):837-45.

24. van Beveren NJ, Krab LC, Swagemakers S, Buitendijk GH, Boot E, van der Spek $\mathrm{P}$, et al. Functional gene-expression analysis shows involvement of schizophrenia-relevant pathways in patients with 22q11 deletion syndrome. PLoS One. 2012;7(3), e33473.

25. de la Morena MT, Eitson JL, Dozmorov IM, Belkaya S, Hoover AR, Anguiano E, et al. Signature MicroRNA expression patterns identified in humans with 22q11.2 deletion/DiGeorge syndrome. Clin Immunol. 2013;147(1):11-22.

26. Ye T, Lipska BK, Tao R, Hyde TM, Wang L, Li C, et al. Analysis of copy number variations in brain DNA from patients with schizophrenia and other psychiatric disorders. Biol Psychiatry. 2012;72(8):651-4.

27. Das Chakraborty R, Bernal AJ, Schoch K, Howard TD, Ip EH, Hooper SR, et al. Dysregulation of DGCR6 and DGCR6L: psychopathological outcomes in chromosome 22q11.2 deletion syndrome. Transl Psychiatry. 2012;2, e105.

28. Ishiguro H, Koga M, Horiuchi Y, Noguchi E, Morikawa M, Suzuki Y, et al. Supportive evidence for reduced expression of GNB1L in schizophrenia. Schizophr Bull. 2010;36(4):756-65.

29. Edelmann L, Stankiewicz P, Spiteri E, Pandita RK, Shaffer L, Lupski JR, et al. Two functional copies of the DGCR6 gene are present on human chromosome 22q11 due to a duplication of an ancestral locus. Genome Res. 2001;11(2):208-17.

30. Maynard TM, Haskell GT, Peters AZ, Sikich L, Lieberman JA, LaMantia AS. A comprehensive analysis of $22 \mathrm{q} 11$ gene expression in the developing and adult brain. Proc Natl Acad Sci U S A. 2003;100(24):14433-8.

31. Beveridge NJ, Gardiner E, Carroll AP, Tooney PA, Cairns MJ. Schizophrenia is associated with an increase in cortical microRNA biogenesis. Mol Psychiatry. 2010;15(12):1176-89

32. Xie Q, Lin T, Zhang Y, Zheng J, Bonanno JA. Molecular cloning and characterization of a human AIF-like gene with ability to induce apoptosis J Biol Chem. 2005;280(20):19673-81.

33. Sellier C, Hwang VJ, Dandekar R, Durbin-Johnson B, Charlet-Berguerand N, Ander BP, et al. Decreased DGCR8 expression and miRNA dysregulation in individuals with 22q11.2 deletion syndrome. PLoS One. 2014;9(8), e103884.

34. Hiroi N, Takahashi T, Hishimoto A, Izumi T, Boku S, Hiramoto T. Copy number variation at 22q11.2: from rare variants to common mechanisms of developmental neuropsychiatric disorders. Mol Psychiatry. 2013;18(11):1153-65.

35. Karayiorgou M, Simon TJ, Gogos JA. 22q11.2 microdeletions: linking DNA structural variation to brain dysfunction and schizophrenia. Nat Rev Neurosci. 2010;11(6):402-16.

36. Merico D, Costain G, Butcher NJ, Warnica M, Ogura L, Alfred SE et al. MicroRNA dysregulation, gene networks and risk for schizophrenia in 22q11.2 deletion syndrome. Frontiers Neurol. 2014;5(238).

37. Johnson MB, Kawasawa YI, Mason CE, Krsnik Z, Coppola G, Bogdanovic D, et al. Functional and evolutionary insights into human brain development through global transcriptome analysis. Neuron. 2009;62(4):494-509.

38. Moreno-Hagelsieb G, Latimer K. Choosing BLAST options for better detection of orthologs as reciprocal best hits. Bioinformatics. 2008;24(3):319-24

39. Ward N, Moreno-Hagelsieb G. Quickly finding orthologs as reciprocal best hits with BLAT, LAST, and UBLAST: how much do we miss? PLOS One. 2014;9(7), e101850

40. Kozomara A, Griffiths-Jones S. miRBase: annotating high confidence microRNAs using deep sequencing data. Nucleic Acids Res. 2014;42(Database issue):D68-73.

41. Brzustowicz LM, Bassett AS. miRNA-mediated risk for schizophrenia in 22q11.2 deletion syndrome. Front Genet. 2012;3:291.
42. Forstner AJ, Degenhardt F, Schratt G, Nothen MM. MicroRNAs as the cause of schizophrenia in 22q11.2 deletion carriers, and possible implications for idiopathic disease: a mini-review. Front Mol Neurosci. 2013;6:47

43. Warnica W, Merico D, Costain G, Alfred SE, Wei J, Marshall CR, et al. Copy number variable MicroRNAs in schizophrenia and their neurodevelopmental gene targets. Biol Psychiatry. 2014;77(2):158-66.

44. Hu HY, Guo S, Xi J, Yan Z, Fu N, Zhang X, et al. MicroRNA expression and regulation in human, chimpanzee, and macaque brains. PLoS Genet. 2011;7(10), e1002327.

45. Woods IG, Kelly PD, Chu F, Ngo-Hazelett P, Yan YL, Huang H, et al. A comparative map of the zebrafish genome. Genome Res. 2000;10(12):1903-14.

46. Bhutkar A, Russo S, Smith TF, Gelbart WM. Techniques for multi-genome synteny analysis to overcome assembly limitations. Genome Inform. 2006;17(2):152-61.

47. St JD. The art and design of genetic screens: drosophila melanogaster. Nat Rev Genet. 2002;3(3):176-88.

48. Wang Z, Sherwood DR. Dissection of genetic pathways in C. elegans. Methods Cell Biol. 2011;106:113-57.

49. Schub T. Pathology of mutant animal models 2001. Lab Anim (NY). 2001;30(5):30.

50. Sanders LH, Whitlock KE. Phenotype of the zebrafish masterblind (mbl) mutant is dependent on genetic background. Dev Dyn. 2003;227(2):291-300.

51. Chandler $\mathrm{CH}$, Chari S, Tack DI. Causes and consequences of genetic background effects illuminated by integrative genomic analysis. Genetics. 2014;196(4):1321-36

52. Barriere A, Felix MA. Natural variation and population genetics of Caenorhabditis elegans. WormBook; 2005: p. 1-19.

53. Gogos JA, Santha M, Takacs Z, Beck KD, Luine V, Lucas LR, et al. The gene encoding proline dehydrogenase modulates sensorimotor gating in mice. Nat Genet. 1999:21(4):434-9.

54. Paterlini M, Zakharenko SS, Lai WS, Qin J, Zhang H, Mukai J, et al. Transcriptional and behavioral interaction between 22 q11.2 orthologs modulates schizophrenia-related phenotypes in mice. Nat Neurosci. 2005;8(11):1586-94.

55. Luhur A, Chawla G, Wu YC, Li J, Sokol NS. Drosha-independent DGCR8/ Pasha pathway regulates neuronal morphogenesis. Proc Natl Acad Sci U S A. 2014;111(4):1421-6.

56. Hall B, Limaye A, Kulkarni AB. Overview: generation of gene knockout mice Curr Protoc Cell Biol. 2009;Chapter 19:Unit 191219 12 1-17.

57. Ran FA, Hsu PD, Wright J, Agarwala V, Scott DA, Zhang F. Genome engineering using the CRISPR-Cas9 system. Nat Protoc. 2013;8(11):2281-308.

58. Buckingham SD, Esmaeili B, Wood M, Sattelle DB. RNA interference: from model organisms towards therapy for neural and neuromuscular disorders Hum Mol Genet. 2004;13 Spec No 2:R275-88.

59. Wang Y, Wu L, Wang P, Lv C, Yang Z, Tang X. Manipulation of gene expression in zebrafish using caged circular morpholino oligomers. Nucleic Acids Res. 2012;40(21):11155-62.

60. Nasevicius A, Ekker SC. Effective targeted gene 'knockdown' in zebrafish. Nat Genet. 2000;26(2):216-20.

61. Tischler J, Lehner B, Chen N, Fraser AG. Combinatorial RNA interference in Caenorhabditis elegans reveals that redundancy between gene duplicates can be maintained for more than 80 million years of evolution. Genome Biol. 2006;7(8):R69.

62. Schmid A, Schindelholz B, Zinn K. Combinatorial RNAi: a method for evaluating the functions of gene families in Drosophila. Trends Neurosci. 2002;25(2):71-4.

63. Hayward DC, Delaney SJ, Campbell HD, Ghysen A, Benzer S, Kasprzak AB, et al. The sluggish-A gene of Drosophila melanogaster is expressed in the nervous system and encodes proline oxidase, a mitochondrial enzyme involved in glutamate biosynthesis. Proc Natl Acad Sci U S A. 1993;90(7):2979-83.

64. Goodman BK, Rutberg J, Lin WW, Pulver AE, Thomas GH. Hyperprolinaemia in patients with deletion (22)(q11.2) syndrome. J Inherit Metab Dis. 2000;23(8):847-8.

65. Jacquet $H$, Berthelot J, Bonnemains C, Simard G, Saugier-Veber P, Raux G, et al. The severe form of type I hyperprolinaemia results from homozygous inactivation of the PRODH gene. J Med Genet. 2003;40(1), e7.

66. Swillen A, Devriendt K, Legius E, Prinzie P, Vogels A, Ghesquiere P, et al. The behavioural phenotype in velo-cardio-facial syndrome (VCFS): from infancy to adolescence. Genet Couns. 1999;10(1):79-88. 
67. Boot $E$, Butcher NJ, van Amelsvoort TA, Lang AE, Marras C, Pondal M, et al. Movement disorders and other motor abnormalities in adults with 22q11.2 deletion syndrome. Am J Med Genet A. 2015;167A(3):639-45.

68. Catalina-Rodriguez O, Kolukula VK, Tomita Y, Preet A, Palmieri F, Wellstein A, et al. The mitochondrial citrate transporter, $\mathrm{ClC}$, is essential for mitochondrial homeostasis. Oncotarget. 2012;3(10):1220-35.

69. Poling JS, Frye RE, Shoffner J, Zimmerman AW. Developmental regression and mitochondrial dysfunction in a child with autism. J Child Neurol. 2006;21(2):170-2

70. Prabakaran S, Swatton JE, Ryan MM, Huffaker SJ, Huang JT, Griffin JL, et al. Mitochondrial dysfunction in schizophrenia: evidence for compromised brain metabolism and oxidative stress. Mol Psychiatry. 2004;9(7):684-97.

71. Ramsey CP, Giasson BI. Role of mitochondrial dysfunction in Parkinson's disease: Implications for treatment. Drugs Aging. 2007;24(2):95-105.

72. Scorrano L. Keeping mitochondria in shape: a matter of life and death. Eur J Clin Invest. 2013;43(8):886-93.

73. Maynard TM, Meechan DW, Dudevoir ML, Gopalakrishna D, Peters AZ, Heindel CC, et al. Mitochondrial localization and function of a subset of 22 q11 deletion syndrome candidate genes. Mol Cell Neurosci. 2008;39(3):439-51.

74. Cacho-Valadez B, Munoz-Lubato F, Pedrajas JR, Cabello J, Fierro-Gonzalez JC, Navas $P$, et al. The characterization of the Caenorhabditis elegans mitochondrial thioredoxin system uncovers an unexpected protective role of thioredoxin reductase 2 in beta-amyloid peptide toxicity. Antioxid Redox Signal. 2012;16(12):1384-400.

75. Miller RR, Okkema PG. The Caenorhabditis elegans T-box factor MLS-1 requires Groucho co-repressor interaction for uterine muscle specification. PLoS Genet. 2011;7(8), e1002210.

76. Friedel RH, Wurst W, Wefers B, Kuhn R. Generating conditional knockout mice. Methods Mol Biol. 2011;693:205-31.

77. Doetschman T, Azhar M. Cardiac-specific inducible and conditional gene targeting in mice. Circ Res. 2012;110(11):1498-512.

78. van der Weyden L, White JK, Adams DJ, Logan DW. The mouse genetics toolkit: revealing function and mechanism. Genome Biol. 2011;12(6):224.

79. Liu J, Stainier DY. Zebrafish in the study of early cardiac development. Circ Res. 2012;110(6):870-4

80. Bakkers J. Zebrafish as a model to study cardiac development and human cardiac disease. Cardiovasc Res. 2011:91(2):279-88.

81. Packham EA, Brook JD. T-box genes in human disorders. Hum Mol Genet. 2003;12 Spec No 1:R37-44

82. Yamagishi $H$, Srivastava D. Unraveling the genetic and developmental mysteries of 22q11 deletion syndrome. Trends Mol Med. 2003;9(9):383-9.

83. Zhang J, Piontek J, Wolburg H, Piehl C, Liss M, Otten C, et al. Establishment of a neuroepithelial barrier by Claudin5a is essential for zebrafish brain ventricular lumen expansion. Proc Natl Acad Sci U S A. 2010;107(4):1425-30.

84. Green T, Gothelf D, Glaser B, Debbane M, Frisch A, Kotler M, et al. Psychiatric disorders and intellectual functioning throughout development in velocardiofacial (22q11.2 deletion) syndrome. J Am Acad Child Adolesc Psychiatry. 2009:48(11):1060-8.

85. van Alphen B, van Swinderen B. Drosophila strategies to study psychiatric disorders. Brain Res Bull. 2013;92:1-11.

86. Jeibmann A, Paulus W. Drosophila melanogaster as a model organism of brain diseases. Int J Mol Sci. 2009;10(2):407-40.

87. Pandey UB, Nichols CD. Human disease models in Drosophila melanogaster and the role of the fly in therapeutic drug discovery. Pharmacol Rev. 2011;63(2):411-36

88. Oortveld MA et al. Human intellectual disability genes form conserved functional modules in Drosophila. PLoS Genet. 2013;9(10), e1003911.

89. Silverman GA, Luke CJ, Bhatia SR, Long OS, Vetica AC, Perlmutter DH, et al. Modeling molecular and cellular aspects of human disease using the nematode Caenorhabditis elegans. Pediatr Res. 2009;65(1):10-8.

90. Kaletta T, Hengartner MO. Finding function in novel targets: C. elegans as a model organism. Nat Rev Drug Discov. 2006;5(5):387-98.

91. Tomari Y, Zamore PD. MicroRNA biogenesis: drosha can't cut it without a partner. Curr Biol. 2005;15(2):R61-4.

92. Stark KL, Xu B, Bagachi A, Lai WS, Liu H, Hsu R, et al. Altered brain microRNA biogenesis contributes to phenotypic deficits in a 22q11-deletion mouse model. Nat Genet. 2008;40(6):751-60.

93. Wightman B, Ha I, Ruvkun G. Posttranscriptional regulation of the heterochronic gene lin-14 by lin-4 mediates temporal pattern formation in C. elegans. Cell. 1993;75(5):855-62.
94. Lee RC, Feinbaum RL, Ambros V. The C. elegans heterochronic gene lin-4 encodes small RNAs with antisense complementarity to lin-14. Cell. 1993;75(5):843-54.

95. Pasquinelli AE, Reinhart BJ, Slack F, Martindale MQ, Kuroda MI, Maller B, et al. Conservation of the sequence and temporal expression of let-7 heterochronic regulatory RNA. Nature. 2000;408(6808):86-9.

96. Park CY, Choi YS, McManus MT. Analysis of microRNA knockouts in mice. Hum Mol Genet. 2010;19(R2):R169-75.

97. Mishima Y. Widespread roles of microRNAs during zebrafish development and beyond. Dev Growth Differ. 2012;54(1):55-65.

98. Dai Q, Smibert P, Lai EC. Exploiting Drosophila genetics to understand microRNA function and regulation. Curr Top Dev Biol. 2012;99:201-35.

99. Giot L, Bader JS, Brouwer C, Chaudhuri A, Kuang B, Li Y, et al. A protein interaction map of Drosophila melanogaster. Science. 2003;302(5651):1727-36.

100. Denli AM, Tops BB, Plasterk RH, Ketting RF, Hannon GJ. Processing of primary microRNAs by the Microprocessor complex. Nature. 2004;432(7014):231-5.

101. Lehrbach NJ, Castro C, Murfitt KJ, Abreu-Goodger C, Griffin JL, Miska EA. Post-developmental microRNA expression is required for normal physiology, and regulates aging in parallel to insulin/IGF-1 signaling in C. elegans. RNA. 2012;18(12):2220-35.

102. Bassett AS, Chow EW, Husted J, Hodgkinson KA, Oechslin E, Harris L, et al. Premature death in adults with 22q11.2 deletion syndrome. J Med Genet. 2009;46(5):324-30.

103. Kraemer BC, Burgess JK, Chen JH, Thomas JH, Schellenberg GD, et al. Molecular pathways that influence human tau-induced pathology in Caenorhabditis elegans. Hum Mol Genet. 2006;15(9):1483-96.

104. Roizen NJ, Higgins AM, Antshel KM. Fremont, Shprintzen R, Kates WR. 22q11.2 deletion syndrome: are motor deficits more than expected for IQ level? J Pediatr. 2010;157(4):658-61.

105. Van Aken K, Caeyenberghs K, Smits-Engelsman B, Swillen A. The motor profile of primary school-age children with a 22q11.2 deletion syndrome (22q11.2DS) and an age- and IQ-matched control group. Child Neuropsychol. 2009;15(6):532-42.

106. Noma K, Goncharov A, Jin Y. Systematic analyses of rpm-1 suppressors reveal roles for ESS-2 in mRNA splicing in Caenorhabditis elegans. Genetics. 2014;198(3):1101-15.

107. Xiong HY, Alipanahi B, Lee LJ, Bretschneider H, Merico D, Yuen RK, et al. RNA splicing. The human splicing code reveals new insights into the genetic determinants of disease. Science. 2015;347(6218):1254806.

108. Giacomotto J, Segalat L. High-throughput screening and small animal models, where are we? Br J Pharmacol. 2010;160(2):204-16.

109. Whisstock JC, Lesk AM. Prediction of protein function from protein sequence and structure. Q Rev Biophys. 2003;36(3):307-40.

110. Punta $M$, Ofran $Y$. The rough guide to in silico function prediction, or how to use sequence and structure information to predict protein function. PLoS Comput Biol. 2008:4(10), e1000160.

111. Bender HU, Almashanu S, Steel G, Hu CA, Lin WW, Willis A, et al. Functional consequences of PRODH missense mutations. Am J Hum Genet. 2005;76(3):409-20.

112. Ratti A, Amati F, Bozzali M, Conti E, Sangiuolo F, Bercolo M, et al. Cloning and molecular characterization of three ubiquitin fusion degradation 1 (Ufd1) ortholog genes from Xenopus laevis, Gallus gallus and Drosophila melanogaster. Cytogenet Cell Genet. 2001;92(3-4):279-82.

113. Hierck BP, Molin DG, Boot MJ, Poelmann RE, Gittenberger-de Groot AC. A chicken model for DGCR6 as a modifier gene in the DiGeorge critical region. Pediatr Res. 2004;56(3):440-8.

114. Pukkila-Worley R, Feinbaum RL, McEwan DL, Conery AL, Ausubel FM. The evolutionarily conserved mediator subunit MDT-15/MED15 links protective innate immune responses and xenobiotic detoxification. PLoS Pathog. 2014; 10(5), e1004143

115. Shang P, Hoogerbrugge J, Baarends WM, Grootegoed JA. Evolution of testis-specific kinases TSSK1B and TSSK2 in primates. Andrology. 2013;1(1):160-8.

116. Sibbing D, Pfeufer A, Perisic A, Mannes AM, Fritz-Wolf K, Unwin S, et al. Mutations in the mitochondrial thioredoxin reductase gene TXNRD2 cause dilated cardiomyopathy. Eur Heart J. 2011;32(9):1121-33. 